\title{
Dystrophic Calcification
}

National Cancer Institute

\section{Source}

National Cancer Institute. Dystrophic Calcification. NCI Thesaurus. Code C35992.

Calcium deposits in degenerated or necrotic tissue without abnormalities in blood calcium. 